\title{
Seleção de Plantas Resistentes e de Fungicidas para o Controle da Podridão do Colo do Maracujazeiro Causada por Nectria haematococca*
}

\author{
Ivan H. Fischer, Silvia A. Lourenço, Marise C. Martins, Hiroshi Kimati \& Lilian Amorim
}

Departamento de Entomologia, Fitopatologia e Zoologia Agrícola, Escola Superior de Agricultura "Luiz de Queiroz", Universidade de São Paulo, Cx. Postal 9, CEP 13418-900, Piracicaba, SP, fax (019) 3434-4839, e-mail: ihfische@esalq.usp.br

(Aceito para publicação em 12/01/2005)

Autor para correspondência: Ivan H. Fischer

FISCHER, I.H., LOURENÇO, S.A., MARTINS, M.C., KIMATI, H. \& AMORIM, L. Seleção de plantas resistentes e de fungicidas para o controle da podridão do colo do maracujazeiro causada por Nectria haematococca. Fitopatologia Brasileira 30:250-258. 2005.

\section{RESUMO}

A podridão do colo do maracujazeiro (Passiflora edulis f. flavicarpa), causada por Nectria haematococca e Phytophthora spp., é um dos principais problemas da cultura no Brasil, sendo responsável pelo decréscimo da produtividade e constantes migrações da cultura. O controle da doença é basicamente preventivo, visando a não introdução dos patógenos na área. O presente trabalho visou 1) avaliar métodos de inoculação de $N$. haematococca e a suscetibilidade do maracujazeiro amarelo ao patógeno em diferentes idades; 2) a ocorrência de "damping-off"; 3) o comportamento de diferentes espécies do gênero Passiflora e de genótipos de $P$. edulis f.flavicarpa ao patógeno; e 4) realizar testes de controle químico. Inoculações no colo de maracujazeiro amarelo proporcionaram maiores níveis de doença comparadas às inoculações no sistema radicular. Os resultados sugerem que $N$. haematococca seja um patógeno que penetra por ferimentos. A mortalidade foi maior quando a inoculação foi realizada em plantas mais jovens e quando $N$. haematococca e Phytophthora nicotianae estavam associados. Dentre as 17 espécies do gênero Passiflora avaliadas para resistência a $N$. haematococca, P. nitida, P. laurifolia e P. alata foram as menos lesionadas. Os genótipos de P. edulis f. flavicarpa mais resistentes ao patógeno foram os procedentes de Morretes (PR), Sapucaí (SP) e a cultivar Maguari. Os fungicidas prochloraz, thiabendazole, thiram+thiabendazole, carbendazim, triflumizole e captan exerceram controle erradicante em solo infestado com $N$. haematococca. Os fungicidas prochloraz e carbendazim evitaram a morte de plantas em tratamento curativo, com os melhores resultados quando aplicados dois dias após a inoculação, comparado a sete dias.

Palavras-chave adicionais: Passifloraceae, resistência genética, controle químico.

\begin{abstract}
Selection of resistant plants and fungicides for the control of passion fruit collar rot, caused by Nectria haematococca

The collar rot of passion fruit (Passiflora edulis f.flavicarpa), caused by Nectria haematococca and Phytophthora spp., is one of the main problems of the passion fruit producing areas in Brazil, and is responsible for yield decrease and constant migrations of the culture. The control of the disease is basically preventive, and directed to avoiding the introduction of the pathogen in the area. The objectives of this research were: 1) to evaluate methods of inoculation of $N$. haematococca and the suscetibility of yellow passion fruit at different ages; 2) to evaluate "damping-off"; 3) to evaluate the behavior of different species of genera Passsiflora and different genotyps of $P$. edulis f. flavicarpa to the pathogen; and 4) to carry out tests of chemical control. Inoculations in the collar zone of plants provided higher levels of disease compared to inoculations in the radicular system. These results suggest that $N$. haematococca penetrates through wounds. Mortality was higher in younger plants and when N. haematococca and Phytophthora nicotianae were together. Among the 17 species of genus Passiflora tested for N. haematococca, P. nitida, P. laurifolia, and P. alata showed the lowest average number of lesions. The most resistant genotypes of $P$. edulis f. flavicarpa to $N$. haematococca were those from Morretes (PR), Sapucaí (SP), and the Maguari variety. Prochloraz, thiabendazole, thiram+thiabendazole, carbendazim, triflumizole, and captan controlled $N$. haematococca. The fungicides tested for curative treatment inhibited the development of the disease most effectvely when applied two days after inoculation when compared to seven days. Prochloraz and carbendazim were outstanding for preventing the death of plants inoculated with $N$. haematococca.
\end{abstract}

Additional keywords: Passifloraceae, genetic resistance, chemical control.

\section{INTRODUÇÃO}

O Brasil, centro de origem de um grande número de espécies da família Passifloraceae, destaca-se como o maior

*Parte da Dissertação do primeiro autor parcialmente financiada pela FAPESP (01/12432-5). produtor mundial do maracujá-amarelo (Passiflora edulis $\mathrm{f}$. flavicarpa Deg.). Um dos fatores da baixa produtividade do maracujazeiro é a ocorrência de doenças, principalmente a podridão do colo que mata precocemente as plantas, antes de completarem dois anos de idade. A doença é observada em plantas adultas, porém sob condições favoráveis, como o 
plantio em solos com histórico da doença e elevada temperatura e umidade, as plantas novas podem sucumbir ao ataque dos patógenos (Melo et al., 1990; Ponte et al., 1998). Esse processo inicia-se com o amarelecimento e perda de turgescência dos brotos, seguida de murcha e seca da planta, resultado da podridão do colo e do sistema radicular.

Nectria haematococca Berk \& Br. [F. anamórfica: Fusarium solani (Mart.) Sacc.] é considerado o principal agente causal da podridão do colo do maracujazeiro. De acordo com Ponte et al. (1998), este fungo está disperso por todos os Estados brasileiros produtores, sendo responsável, em muitos casos, por constantes migrações da cultura. Phytophthora spp. pode também estar associado aos sintomas da doença (Ponte, 1993), podendo ainda atuar concomitantemente a $N$. haematococca (Cole et al., 1992; Fischer et al., 2003a). Phytophthora nicotianae Breda de Haan também pode ser o responsável por sintomas de "damping-off" em viveiros de maracujá (Cole et al.,1992; Gonzalez et al., 2000).

No Zimbábue a doença é causada pelo complexo dos patógenos $N$. haematococca e P. nicotianae (Cole et al., 1992). O fungo $N$. haematococca foi constantemente isolado de plantas doentes, mas quando inoculado isoladamente o progresso da doença foi relativamente lento. Plantas de dois meses de idade mostraram sintomas de murcha após três dias de inoculação com $P$. nicotianae ou $P$. nicotianae mais $N$. haematococca, comparado a 16 dias quando inoculado apenas com N. haematococca (Cole et al., 1992).

Plantas jovens apresentam maior suscetibilidade aos patógenos em função do menor diâmetro no córtex do colo e do sistema radicular (Cole et al., 1992). Experimentalmente, o número de mortes devido à inoculação com $N$. haematococca foi maior em plantas de dez semanas de idade do que em plantas de 12 meses de idade (Emechebe \& Mukiibi, 1976). Ferimentos no colo e raízes também aumentam a suscetibilidade à invasão do patógeno (Cole et al., 1992). Lin \& Chang (1985) e Cedeño et al. (1990) só reproduziram a doença quando foram realizados ferimentos previamente à inoculação.

Como medidas de controle da podridão do colo do maracujazeiro recomenda-se evitar o plantio em solos pesados e compactados, corrigir o $\mathrm{pH}$ do solo e manter a integridade do sistema radicular, erradicando as plantas doentes (Ruggiero et al., 1996).

Nunes \& Albuquerque (1995) constataram que aplicações de benomyl e captan contribuem para prevenir o avanço das infecções de $N$. haematococca. Ponte et al. (1998) verificaram que covas tratadas com pentacloronitrobenzeno e com calcário preveniram a doença, com uma redução de $44,7 \%$ e $48,5 \%$, respectivamente. Ponte (1993) obteve um bom índice de controle (75\%) com a aplicação de $5 \mathrm{Kg}$ de esterco bovino nas covas. Todavia, isto foi verificado em solo onde Trichoderma spp. estava presente, ao contrário do que Ponte et al. (1998) verificaram com a aplicação de esterco bovino em solo sem a presença de Trichoderma spp.. É sabido que a matéria orgânica estimula o crescimento desses fungos reconhecidos como antagonistas de Fusarium spp. Ssekyewa et al. (1999), aplicando oxicloreto de cobre (60 g/20 1 de água) no colo da planta a intervalos bissemanais, conseguiram reduzir em $65 \%$ a incidência da doença.

Em estudos de resistência a $N$. haematococca, Delanoë (1991) relatou a ocorrência de resistência em Passiflora candida Mast. e $P$. fuchsiiflora Hemsl., enquanto $P$. coccinea Aubl., P. laurifolia L. e P. glandulosa Cav. foram parcialmente resistentes. Algumas linhagens de $P$. edulis f. flavicarpa apresentaram-se resistentes quando comparadas a $P$. edulis $\mathrm{f}$. edulis Sims (Lin \& Chang, 1985). Segundo Ssekyewa et al. (1999), tanto P. edulis f. flavicarpa quanto P. maliformis L. são parcialmente resistentes ao patógeno e podem ser recomendados para uso como porta-enxerto em $P$. edulis $\mathrm{f}$. edulis e híbridos suscetíveis. Cole et al. (1992) relataram a resistência de $P$. caerulea L. a $N$. haematococca do maracujazeiro.

O presente trabalho visou avaliar métodos de inoculação de $N$. haematococca em maracujazeiro e a suscetibilidade de P. edulis f.flavicarpa em diferentes idades; quantificar a ocorrência de "damping-off" em solo infestado com $N$. haematococca e P. nicotianae isoladamente e em associação; avaliar a suscetibilidade de diferentes espécies do gênero Passsiflora e de genótipos de maracujá-amarelo ao patógeno; realizar testes de controle químico in vitro, tratamento químico erradicante e tratamento químico curativo em P. edulis f. flavicarpa para o patógeno.

\section{MATERIAL E MÉTODOS}

O trabalho foi realizado nos laboratórios e na área experimental do Setor de Fitopatologia, da Escola Superior de Agricultura "Luiz de Queiroz" (ESALQ), Universidade de São Paulo (USP), Campus de Piracicaba, SP.

Os isolados de $N$. haematococca foram provenientes de maracujazeiros doentes, obtidos de consultas enviadas para análise na Clínica Fitopatológica da ESALQ/USP e de campos comerciais de maracujá. Oito isolados de N. haematococca, sendo um procedente de Sussuarana (BA), um de Vera Cruz, um de Monte Azul Paulista, dois de Jaú e três de Populina (SP) foram obtidos e tiveram a patogenicidade confirmada em plantas de maracujá-amarelo. O isolado de P. nicotianae, empregado no experimento de "damping-off" foi isolado concomitantemente a $N$. haematococca de maracujazeiros doentes, procedentes de Vera Cruz (SP).

\section{Isolamento e patogenicidade de Nectria haematococca}

Para o isolamento de $N$. haematococca, porções do tecido do colo de plantas infetadas foram cortadas e desinfestadas em hipoclorito de sódio a $0,5 \%$ por $1 \mathrm{~min}$, divididas em fragmentos menores e plaqueadas em meio de cultura ágar-água (AA). As colônias desenvolvidas foram repicadas para o meio de cultura batata-dextrose-ágar (BDA) e identificadas com base em caracteres morfológicos (Booth, 1977). Para a produção de peritécios de N. haematococca, o mesmo foi cultivado em meio de cultura $\mathrm{V} 8-\mathrm{CaCO}_{3}$-ágar ou sobre discos de folha de maracujazeiro depositados sobre o 
meio de cultura, mantidos a $25^{\circ} \mathrm{C}$ e luz fluorescente contínua por cerca de dez dias.

Plantas de maracujá-amarelo de três semanas foram inoculadas com um disco de micélio do patógeno, de $5 \mathrm{~mm}$ de diâmetro, crescido em BDA, e fixado com fita adesiva sobre um pequeno ferimento, no colo da planta (Fischer et al., 2003b). As plantas foram mantidas em casa de vegetação, com o solo constantemente úmido após a inoculação.

As plantas foram avaliadas pela presença e desenvolvimento de lesões necróticas, intumescimento do colo e interferência no desenvolvimento vegetativo. A presença de $N$. haematococca foi confirmada pelo reisolamento do patógeno das porções sintomáticas.

\section{Metodologia de inoculação e suscetibilidade das plantas em diferentes idades}

Plantas de P. edulis f. flavicarpa com seis semanas pós-germinação, crescidas em vasos contendo 21 de solo autoclavado foram inoculadas através de cinco métodos: 1 . Imersão de raízes lavadas e cortadas a $2 \mathrm{~cm}$ de suas extremidades, por $10 \mathrm{~min}$, em suspensão de esporos $\left(10^{6}\right.$ conídios/ml) da fase anamórfica de $N$. haematococca (Cole et al., 1992); 2. Adição de $20 \mathrm{ml}$ de suspensão de esporos $\left(10^{6}\right.$ conídios $\left./ \mathrm{ml}\right)$ de $N$. haematococca no colo das plantas (Lin \& Chang, 1985); 3. Adição de $20 \mathrm{ml}$ de suspensão de esporos $\left(10^{6}\right.$ conídios $\left./ \mathrm{ml}\right)$ em plantas com ferimentos no sistema radicular, provocados por $15 \mathrm{~cm}$ da lâmina de uma faca inserida no solo, a uma distância de $2 \mathrm{~cm}$ do colo das plantas, deslocando-a por toda a extensão do vaso (Lin \& Chang, 1985); 4. Adição de $20 \mathrm{ml}$ de suspensão de esporos $\left(10^{6}\right.$ conídios $\left./ \mathrm{ml}\right)$ em um ferimento circular de $3 \mathrm{~mm}$ de diâmetro, feito com auxílio de um furador, no colo das plantas ao nível do solo (Lin \& Chang, 1985); 5. Fixação com fita adesiva de um disco de micélio do patógeno, de $5 \mathrm{~mm}$ de diâmetro, crescido em BDA, sobre um ferimento circular de $3 \mathrm{~mm}$ de diâmetro no colo das plantas a uma altura de $2 \mathrm{~cm}$ do solo, removendo-se a fita adesiva após cinco dias (Fischer et al. 2003b).

A suspensão de conídios de $N$. haematococca foi preparada em água destilada, raspando-se com uma alça de Drigalsky as placas contendo meio BDA colonizado pelo patógeno por dez dias. A concentração da suspensão foi ajustada com auxílio de um hemocitômetro.

Para avaliar a suscetibilidade de plantas de diferentes idades ao patógeno, utilizaram-se plantas com três, seis, nove e 12 semanas após a germinação e dois métodos de inoculação: do sistema radicular (método 1) e do colo da planta (método 5). Sementes de maracujá amarelo cultivar Sul-Brasil foram utilizadas, pois as mesmas originaram plântulas que se mostraram suscetíveis ao patógeno. Testes preliminares com os diferentes isolados de $N$. haematococca evidenciaram maior agressividade do isolado de Vera Cruz (SP), razão pela qual o mesmo foi escolhido como fonte de inóculo para os experimentos. A distribuição dos vasos no interior da casa de vegetação seguiu um delineamento experimental inteiramente ao acaso, com cinco e seis plantas (repetições) para os ensaios de metodologias de inoculação e idade das plantas, respectivamente. Avaliou-se o comprimento $(\mathrm{cm})$ de lesões desenvolvidas acima do nível do solo ou o número de plantas mortas.

\section{"Damping-off" em solo infestado com $N$. haematococca e $P$. nicotianae isoladamente e em associação}

Sementes de maracujá amarelo foram semeadas, semanalmente, em vasos contendo solo autoclavado, deixandose após o desbaste 15 plântulas por vaso. Solo autoclavado foi infestado com uma suspensão de conídios e micélio de $N$. haematococca, $P$. nicotianae ou $N$. haematococca $+P$. nicotianae, na razão de uma placa de Petri, contendo o meio de cultura BDA colonizado, para cada $250 \mathrm{ml}$ de solo. O solo infestado foi mantido constantemente úmido e após duas semanas, período este que permite a estabilização da população dos fitopatógenos (Mitchell \& KannwischerMitchell, 1992), o solo foi então, peneirado, homogeneizado e colocado sobre os vasos, na razão de $250 \mathrm{~g}$ de solo infestado por vaso, cobrindo diretamente as sementes da última semeadura ou o colo das plântulas anteriormente semeadas.

Avaliou-se, semanalmente, a incidência da doença, ou seja, o número de plântulas tombadas ou com sintomas terminais de murcha e seca da parte aérea.

\section{Suscetibilidade de espécies Passiflora e de genótipos de $\boldsymbol{P}$. edulis f. flavicarpa a $N$. haematococca}

Sementes de diferentes espécies do gênero Passiflora (P. alata Dryander, P. caerulea, P. cincinnata Mast., $P$. coccinea, $P$. serrato-digitata L., P. edulis f. edulis, P. edulis f. flavicarpa, $P$. foetida L., $P$. giberti Brown, $P$. laurifolia, $P$. maliformis, P. morifolia Mast., P. nitida HBK., P. pohlii Mast., P. quadrangularis L., P. setacea DC., P. sidaefolia M. Roemer e P. suberosa L.) e de genótipos de P. edulis f. flavicarpa, procedentes do Instituto Agronômico de Campinas (IAC), do Departamento de Genética da ESALQ/USP, do Campus da UNESP de Jaboticabal, das empresas Maguari e AFRUVEC (Associação dos Fruticultores da Região de Vera Cruz) e do entreposto comercial da CEAGESP de São Paulo, foram semeadas em vasos contendo 21 de solo autoclavado, deixando-se após o desbaste uma planta por vaso. Plantas de seis semanas pós-germinação foram inoculadas com um disco de micélio de $N$. haematococca, no colo da planta (método 5). Cinco meses após a inoculação, as espécies de Passiflora sobreviventes foram reinoculadas, conforme método 3, buscando avaliar a suscetibilidade das plantas inoculadas via sistema radicular. A distribuição dos vasos no interior da casa de vegetação seguiu um delineamento experimental inteiramente ao acaso, com cinco e seis plantas (repetições) para as espécies do gênero Passiflora e genótipos de maracujáamarelo, respectivamente.

Os dois genótipos de P. edulis f. flavicarpa mais resistentes ao isolado de Nectria sp. de Vera Cruz, assim como os dois mais suscetíveis, foram novamente avaliados em outro experimento, semelhante ao primeiro, em que a suscetibilidade dos genótipos foi avaliada para cinco isolados de $N$. haematococca. 
Inibição in vitro do crescimento micelial de $N$. haematococca

Os fungicidas foram diluídos em série e ajustados para as concentrações de 1,10 e $100 \mathrm{ppm}$ de ingrediente ativo, adicionados ao meio de cultura BDA fundente, a $45-50{ }^{\circ} \mathrm{C}$, com $20 \mathrm{ml}$ vertidos em cada placa de Petri de $90 \mathrm{~mm}$ de diâmetro. Após resfriamento do meio, transferiu-se um disco de micélio de $5 \mathrm{~mm}$ de diâmetro de $N$. haematococca em crescimento ativo em BDA com aproximadamente sete dias de repicagem.

As placas permaneceram a uma temperatura aproximada de $26^{\circ} \mathrm{C}$, no escuro, por um período de sete dias. A eficiência dos produtos foi verificada através da medida perpendicular dos diâmetros das colônias em milímetros, determinando-se a porcentagem de inibição dos tratamentos em relação à testemunha sem fungicida.

$\mathrm{O}$ delineamento experimental foi inteiramente casualizado, com cinco repetições, sendo cada parcela representada por uma placa de Petri. Para a análise estatística, os dados foram transformados em arc sen $(\mathrm{x} / 100)^{1 / 2} \mathrm{e}$ as médias comparadas pelo teste de Tukey a 5\% de probabilidade.

\section{Tratamento químico erradicante em solo infestado}

O patógeno $N$. haematococca foi cultivado em BDA contido em placas de Petri por um período aproximado de sete dias. Após esse período, o meio de cultura colonizado foi triturado em liquidificador, com $100 \mathrm{ml}$ de água destilada. Solo autoclavado foi infestado com a suspensão de conídios e micélio de $N$. haematococca, na razão de uma placa de Petri colonizada para cada $250 \mathrm{ml}$ de solo. Quatorze dias após, o solo foi peneirado, homogeneizado e $100 \mathrm{ml}$ do solo infestado foi transferido para sacos de plástico, de 11 de capacidade, contendo uma plântula de maracujá-amarelo 'Sul-Brasil', de cinco semanas pós-germinação. Em seguida, estes receberam $100 \mathrm{ml}$ de calda fungicida dos seis produtos que se mostraram mais eficientes no controle in vitro, nas seguintes doses ( $\mathrm{g}$ ou $\mathrm{ml}$ de i.a./100 1 de água): captan (120 g), carbendazim (50 $\mathrm{ml})$, prochloraz $(67,5 \mathrm{ml})$, thiram + thiabendazole $(86 \mathrm{ml})$, thiabendazole ( $180 \mathrm{~g}$ ) e triflumizole (21 g). Após uma semana, as plântulas sofreram ferimentos, de $3 \mathrm{~mm}$ de diâmetro, no colo ao nível do solo, visando favorecer a ocorrência da doença.

\section{Tratamento químico curativo}

Maracujazeiros da cultivar Sul-Brasil com cinco semanas de idade foram inoculados com uma suspensão de conídios na região do colo previamente ferido (método 4). As plantas receberam, aos dois e sete dias após a inoculação, um tratamento químico com os fungicidas sistêmicos nas mesmas doses e volumes de calda (100 ml/vaso) empregadas no tratamento erradicante, por meio de rega na região do colo acima do ponto de inoculação.

\section{RESULTADOS}

\section{Metodologia de inoculação e idade das plantas}

As lesões no colo das plantas inoculadas pelos métodos
4 e 5 tornaram-se visíveis sete dias após a inoculação. Algumas plantas apresentaram murcha seguida de morte, principalmente nos quatro primeiros meses, com início a partir da quarta semana. Os sintomas de podridão do colo e raízes nas plantas inoculadas pelos métodos 1 e 3 foram mais tardios, ocorrendo a partir do segundo mês. Seis meses após a inoculação, os sintomas praticamente cessaram com a cicatrização das lesões e a sobrevivência das plantas restantes.

Os métodos 4 e 5 foram os que apresentaram maior número de plantas mortas e comprimento de lesões no colo (Tabela 1). A doença não ocorreu nos dez meses de avaliação quando $N$. haematococca foi inoculado na ausência de ferimentos (método 2). De maneira geral, a intensidade da doença foi maior quando as plantas foram inoculadas em março de 2002 comparado a maio do mesmo ano.

O número de plantas mortas e o tamanho das lesões foram decrescentes com a idade, com maior mortalidade em plantas inoculadas três semanas após a germinação. $N$. haematococca não acarretou a morte das plantas de nove e 12 semanas após a germinação nos dois métodos de inoculação adotados, durante dez meses de avaliação do experimento. A doença foi mais severa nas inoculações realizadas em março (Tabela 2).

Ocorrência de "damping-off" em solo infestado com $N$. haematococca e P. nicotianae isoladamente e em associação

Observou-se uma redução crescente no número de plântulas mortas a partir da semeadura resultante do ataque dos patógenos $P$. nicotianae e $N$. haematococca $+P$. nicotianae (Tabela 3). Nectria haematococca isoladamente não causou doença, porém quando em associação a $P$. nicotianae o número de plantas mortas foi superior ao provocado por P. nicotianae isoladamente (Tabela 3). As plantas foram avaliadas semanalmente durante quatro meses, considerando que no último mês não ocorreu a morte de plantas.

\section{Suscetibilidade de espécies Passiflora a $N$. haematococca}

Verificou-se a morte de plantas a partir da terceira semana da inoculação de $N$. haematococca, cessando praticamente o crescimento das lesões após três meses para a maioria das espécies, com a cicatrização das lesões. Após a inoculação do sistema radicular ocorreu a morte de uma repetição das espécies $P$. caerulea, P. sidaefolia, P. maliformis, $P$. suberosa e $P$. setacea. Nas duas últimas espécies, as plantas sobreviventes apresentaram intumescimento do colo ao nível do solo. As espécies $P$. nitida, P. laurifolia e $P$. alata apresentaram as menores médias de lesões de $N$. haematococca, de $0,80,0,85$ e $0,92 \mathrm{~cm}$ de comprimento (Tabela 4), respectivamente. Passiflora sidaefolia e P. edulis f. flavicarpa foram as espécies mais suscetíveis ao patógeno, culminando com a morte de plantas, após três semanas da inoculação. Adicionalmente, P. pohlii, P. edulis f. edulis, P. setacea, $P$. cincinnata, $P$. caerulea, $P$. suberosa e $P$. maliformis apresentaram suscetibilidade a $N$. haematococca. As plantas sobreviventes não apresentaram redução no desenvolvimento 
vegetativo comparado às plantas sadias, nas condições experimentais de casa de vegetação.

\section{Suscetibilidade de genótipos de P. edulis f. flavicarpa a $N$. haematococca}

Observou-se o desenvolvimento das lesões a partir do quinto dia da inoculação de $N$. haematococca. As lesões cessaram o crescimento após oito semanas, considerando que lesões maiores que $2,5 \mathrm{~cm}$ praticamente atingiram o nível do solo, não permitindo avaliar o crescimento descendente das mesmas em direção ao sistema radicular. Embora o número de plantas mortas tenha se concentrado nos três primeiros meses após a inoculação, algumas plantas morreram nos meses seguintes devido ao ataque do patógeno.

Observou-se alta variabilidade dos genótipos (Tabela 5). Destaca-se a existência de genótipos mais resistentes a $N$. haematococca, como o procedente de Morretes (PR) com comprimento médio de lesão de $1,65 \mathrm{~cm}$, seguido pela cultivar Maguari e de Sapucaí (SP), com 2,18 e 2,37 cm de comprimento médio, respectivamente. A cultivar Sul-Brasil, o genótipo de Amparo (SP) e o híbrido IAC 270 podem ser considerados altamente suscetíveis ao patógeno, com sintomas que culminaram com a morte de plantas. Os materiais procedentes de Jacinto Machado (SC), Livramento

TABELA 1 - Comprimento $(\mathrm{cm})$ de lesões ou morte de maracujazeiro amarelo (Passiflora edulis f. flavicarpa) (+) após a inoculação com Nectria haematococca em diferentes métodos de inoculação, realizados em março e maio de 2002

\begin{tabular}{|c|c|c|c|c|c|c|c|c|c|c|}
\hline \multirow{3}{*}{$\begin{array}{l}\text { Repetição } \\
\text { (planta) }\end{array}$} & \multicolumn{10}{|c|}{ Métodos de inocula ção de Nectria haematococca * } \\
\hline & \multicolumn{2}{|c|}{$\begin{array}{l}1 \text { - lesão }(\mathrm{cm}) \\
\text { ou morte }(+)\end{array}$} & \multicolumn{2}{|c|}{$\begin{array}{l}2 \text { - lesão }(\mathrm{cm}) \\
\text { ou morte }(+)\end{array}$} & \multicolumn{2}{|c|}{$\begin{array}{l}\text { 3- lesão }(\mathrm{cm}) \\
\text { ou morte }(+)\end{array}$} & \multicolumn{2}{|c|}{$\begin{array}{l}\text { 4- lesão }(\mathrm{cm}) \\
\text { ou morte }(+)\end{array}$} & \multicolumn{2}{|c|}{$\begin{array}{l}5 \text { - lesão }(\mathrm{cm}) \\
\text { ou morte }(+)\end{array}$} \\
\hline & $\mathbf{1 0 / 0 3}$ & $27 / 05$ & $\mathbf{1 0 / 0 3}$ & $27 / 05$ & $\mathbf{1 0 / 0 3}$ & $27 / 05$ & $\mathbf{1 0 / 0 3}$ & $27 / 05$ & $\mathbf{1 0 / 0 3}$ & $27 / 05$ \\
\hline 1 & + & 0,0 & 0,0 & 0,0 & + & + & + & + & + & + \\
\hline 2 & + & 0,0 & 0,0 & 0,0 & 2,0 & 1,4 & + & 2,6 & + & + \\
\hline 3 & 0,0 & 0,0 & 0,0 & 0,0 & 1,1 & 0,0 & + & 2,5 & + & 1,3 \\
\hline 4 & 0,0 & 0,0 & 0,0 & 0,0 & 0,0 & 0,0 & 2,1 & 0,9 & 2,8 & 1,2 \\
\hline 5 & 0,0 & 0,0 & 0,0 & 0,0 & 0,0 & 0,0 & 1,5 & 0,7 & 2,6 & 1,2 \\
\hline
\end{tabular}

*1. Imersão de raízes lavadas e com suas extremidades cortadas, por $10 \mathrm{~min}$, em suspensão de esporos ( $10^{6}$ conídios/ml) de $N$. haematococca; 2. Adição de $20 \mathrm{ml}$ de suspensão de esporos $\left(10^{6}\right.$ conídios $\left./ \mathrm{ml}\right)$ de $N$. haematococca no colo das plantas; 3 . Adição de $20 \mathrm{ml}$ de suspensão de esporos $\left(10^{6}\right.$ conídios $\left./ \mathrm{ml}\right)$ em plantas com ferimentos no sistema radicular, provocados por $15 \mathrm{~cm}$ da lâmina de uma faca inserida no solo, a 2 cm do colo das plantas, deslocando-a por toda a extensão do vaso; 4. Adição de $20 \mathrm{ml}$ de suspensão de esporos $\left(10^{6}\right.$ conídios $\left./ \mathrm{ml}\right) \mathrm{em}$ um ferimento circular de $3 \mathrm{~mm}$ de diâmetro, no colo das plantas ao nível do solo; 5. Fixação com fita adesiva de um disco de micélio de $N$. haematococca sobre um ferimento no colo da planta, a $2 \mathrm{~cm}$ do solo.

TABELA 2 - Comprimento $(\mathrm{cm})$ de lesões ou número de plantas mortas após a inoculação com Nectria haematococca em maracujazeiros amarelos (Passiflora edulis f. flavicarpa) de diferentes idades

\begin{tabular}{|c|c|c|c|c|c|c|}
\hline \multirow{3}{*}{$\begin{array}{l}\text { Semanas } \\
\text { pós-germinação }\end{array}$} & \multicolumn{6}{|c|}{ Métodos ${ }^{\mathbf{a}}$ - datas de inoculação } \\
\hline & 5 & $03 / 2002$ & $5-$ & $06 / 2002$ & 1 & $06 / 2002$ \\
\hline & Mortes & lesão $(\mathrm{cm})^{\mathbf{b}}$ & Mortes & lesão $(\mathrm{cm})^{\mathbf{b}}$ & Mortes & lesão $(\mathrm{cm})^{\mathrm{h}}$ \\
\hline 3 & 4 & 2,10 & 3 & 1,50 & 0 & 0,0 \\
\hline 6 & 2 & 2,80 & 1 & 1,62 & $\mathbf{0}$ & 0,57 \\
\hline 9 & 0 & 2,92 & 0 & 1,35 & 0 & 0,0 \\
\hline 12 & 0 & 2,32 & 0 & 1,33 & 0 & 0,0 \\
\hline
\end{tabular}

a (5) Fixação com fita adesiva de um disco de micélio de $N$. haematococca sobre um ferimento no colo da planta, a 2 cm do solo. (1) Imersão de raízes lavadas e com suas extremidades cortadas, por $10 \mathrm{~min}$, em suspensão de esporos $\left(10^{6}\right.$ conídios $\left./ \mathrm{ml}\right) \mathrm{de} N$. haematococca;

${ }^{\mathrm{b}}$ Média das plantas sobreviventes de um total de seis plantas.

TABELA 3 - Plântulas mortas de Passiflora edulis f. flavicarpa após a adição de solo infestado com Nectria haematococca e Phytophthora nicotianae, isolada e conjuntamente, no colo de plântulas de diferentes idades

\begin{tabular}{lccccc}
\hline \hline \multirow{2}{*}{ Patógeno } & \multicolumn{5}{c}{ Idade das plântulas na inoculação } \\
\cline { 2 - 6 } & Semeadura & Emergência & $\mathbf{1}$ semana & $\mathbf{2}$ semanas & 3 semanas \\
\hline Nectria haematococca & $\mathbf{0}^{*}$ & $\mathbf{0}^{*}$ & $\mathbf{0}^{*}$ & $\mathbf{0}^{*}$ & $0^{*}$ \\
N. haematococca+ & $\mathbf{6 , 3 3}$ & $\mathbf{6 , 6 7}$ & 3,33 & 3,67 & 1 \\
$\begin{array}{l}\text { Phytophthora nicotianae } \\
\text { P. nicotianae }\end{array}$ & $\mathbf{4 , 3 3}$ & 2 & 1,33 & 1,00 & 1,33 \\
\hline
\end{tabular}

* Média de três vasos contendo 15 plântulas cada. 
(BA), Monte Alegre do Sul e Jaboticabal (SP), foram suscetíveis a $N$. haematococca por apresentarem duas repetições mortas.

No segundo experimento, a cultivar Maguari e o genótipo de Sapucaí foram novamente mais resistentes ao patógeno, apresentando um menor número de plantas mortas, comparados a cultivar Sul-Brasil e o híbrido IAC-270. Observou-se diferença na agressividade entre os isolados de $N$. haematococca, com maior agressividade dos isolados de Sussuarana (BA), Vera Cruz e Populina (SP) (Tabela 6).

Inibição in vitro do crescimento micelial de $N$. haematococca

Os isolados de Nectria sp. de Vera Cruz (SP) e Sussuarana (BA) foram semelhantes quanto à sensibilidade aos fungicidas. A $100 \mathrm{ppm}$ de i.a., somente prochloraz inibiu totalmente o crescimento micelial dos isolados de $N$. haematococca in vitro. Os produtos thiabendazole, thiram + thiabendazole, benomyl e carbendazim também foram altamente eficientes, com inibição superior a $50 \%$ a $1 \mathrm{ppm}$ de i.a., seguidos por triflumizole, captan e tiofanato metílico (Tabela 7).

\section{Tratamento químico erradicante em solo infestado}

Os fungicidas prochloraz, thiabendazole, thiram + thiabendazole, carbendazim, triflumizole e captan empregados como erradicantes em solo infestado com $N$. haematococca

TABELA 4 - Comprimento ( $\mathrm{cm}$ ) de lesões e número de Passifloraceas mortas, um ano após a inoculação com Nectria haematococca

\begin{tabular}{|c|c|c|}
\hline $\begin{array}{l}\text { Espécie de Passiflora } \\
\text { (Procedência) }\end{array}$ & $\begin{array}{l}\text { Médias de } \\
\text { lesões }(\mathrm{cm})^{1}\end{array}$ & $\begin{array}{l}\text { Plantas } \\
\text { mortas }\end{array}$ \\
\hline Passiflora nitida (IAC-Campinas) & $0,80 \mathrm{a}^{2}$ & 0 \\
\hline P. laurifolia (Unesp-Jaboticabal) & 0,85 a & 0 \\
\hline P. alata (Conchal) & 0,92 a & 0 \\
\hline P. alata (São Miguel Arcanjo) & 0,92 a & 0 \\
\hline P. alat a (Esalq - Dep. Genética) & 1,08 a & 0 \\
\hline P. maliformis (IAC) & $1,10 \mathbf{a}$ & 1 \\
\hline$P$ coccinea (IAC) & $1,26 \mathbf{a}$ & 0 \\
\hline P. suberosa (Esalq) & $1,30 \mathbf{a}$ & 1 \\
\hline P. morifolia (Unesp) & $1,32 \mathbf{a}$ & 0 \\
\hline P. quadrangularis (IAC) & $1,33 \mathbf{a}$ & 0 \\
\hline P. serrato-digitata (IAC) & $1,40 \mathrm{ab}$ & 0 \\
\hline P. caerulea (IAC) & $1,44 \mathrm{ab}$ & 1 \\
\hline P. cincinnata (IAC) & $1,63 \mathrm{abc}$ & 1 \\
\hline P. setacea (Unesp) & $1,70 \mathrm{abc}$ & 1 \\
\hline P. edulis f. edulis (IAC) & $1,98 \mathrm{abc}$ & 1 \\
\hline P. foetida (Esalq) & $2,52 \mathrm{bc}$ & 0 \\
\hline P. giberti (Esalq) & $2,60 \mathrm{bc}$ & 0 \\
\hline P. pohlii (IAC) & $2,70 \quad \mathrm{c}$ & 1 \\
\hline P. sidaefolia (IAC) & $1,50^{*}$ & 4 \\
\hline P. edulis f. flavicarpa (AFRUVEC) & $2,13^{*}$ & 2 \\
\hline C.V. (\%) & 33,97 & \\
\hline
\end{tabular}

${ }^{1}$ Média de cinco plantas (repetições). ${ }^{2}$ Médias seguidas por letras iguais na coluna não diferem entre si (Tukey, $\mathrm{p}<0,05)$;

*Média das plantas sobreviventes. inibiram o desenvolvimento de lesões no colo das plantas. Das cinco plantas inoculadas com o patógeno e não submetidas ao tratamento químico, nenhuma havia morrido quatro meses após a inoculação, porém quatro plantas desenvolveram lesões no colo com média de $1,5 \mathrm{~cm}$ de comprimento. O thiabendazole apresentou fitotoxidez na dosagem utilizada (180 g i.a./100 l de água) expressa por necrose foliar e morte de plantas.

\section{Tratamento químico curativo}

Os fungicidas sistêmicos prochloraz, carbendazim, triflumizole e difenoconazole apresentaram inibição do desenvolvimento da doença, quando comparados à testemunha inoculada $\operatorname{com} N$. haematococca que apresentou duas plantas mortas. O prochloraz e o carbendazim destacaram-se em evitar a morte das plantas enquanto que nos tratamentos com triflumizole e difenoconazole houve uma planta morta (Tabela 8). O thiabendazole apresentou fitotoxidez expressa pela morte de três plantas e com o desenvolvimento das duas sobreviventes severamente afetado. $\mathrm{O}$ desenvolvimento da doença foi menor quando os fungicidas foram aplicados dois dias após a inoculação do patógeno comparado aos sete dias. As plantas não inoculadas apresentaram um comprimento médio de lesão cicatrizada de $0,5 \mathrm{~cm}$, decorrente do ferimento com o furador de três milímetros de diâmetro.

TABELA 5 - Comprimento de lesões $(\mathrm{cm})$ e número de plantas mortas de Passiflora edulis f. flavicarpa de diferentes procedências, dez meses após a inoculação com Nectria haematococca no colo das plantas

\begin{tabular}{|c|c|c|}
\hline Passiflora edulis f. flavicarpa* & $\begin{array}{l}\text { Médias de } \\
\text { lesões }(\mathrm{cm})^{1}\end{array}$ & $\begin{array}{l}\text { Plantas } \\
\text { mortas }\end{array}$ \\
\hline Morretes (PR) & $1,65 \mathrm{a}^{2}$ & 0 \\
\hline Maguari(Araguari/MG) & $2,18 \mathrm{ab}$ & 0 \\
\hline Sapucaí (SP) & $2,37 \mathbf{a b}$ & 0 \\
\hline Livramento (BA) & $2,68 \mathrm{abc}$ & 0 \\
\hline Ouro Verde (SP) & $2,72 \mathbf{a b c}$ & 0 \\
\hline Aracruz (ES) & $2,85 \mathrm{abc}$ & 0 \\
\hline IAC-275 & $2,95 \mathrm{abc}$ & 0 \\
\hline São Miguel Arcanjo (SP) & $3,00 \mathrm{abc}$ & 1 \\
\hline Pariquera-açu (SP) & $3,10 \mathbf{a b c}$ & 1 \\
\hline IAC-273 & 3,24 abc & 1 \\
\hline L13P2 (IAC) & $3,56 \mathrm{abc}$ & 1 \\
\hline Adamantina (SP) & 3,78 bc & 0 \\
\hline Itapetininga (SP) & $3,97 \mathrm{bc}$ & 0 \\
\hline IAC-277 & $4,42 \quad c$ & 0 \\
\hline Jacinto Machado (SC) & $2,03 * *$ & 2 \\
\hline Amparo (SP) & $2,75 * *$ & 4 \\
\hline Livramento (BA) & $2,77 * *$ & 2 \\
\hline Monte Alegre do Sul (SP) & $2,83 * *$ & 2 \\
\hline Sul -Brasil (Vera Cruz/SP) & $2,95 * *$ & 3 \\
\hline Jaboticabal (SP) & $3,30 * *$ & 2 \\
\hline IAC-270 & $4,13 * *$ & 3 \\
\hline C.V. $(\%)$ & 32,18 & \\
\hline
\end{tabular}




\section{DISCUSSÃO}

A freqüência de isolamento de $N$. haematococca em plantas de maracujazeiro com podridão do colo leva a acreditar que este fungo seja o responsável pelo caráter itinerante da cultura a partir da década de 70 no Estado de São Paulo.

Os resultados obtidos com as metodologias de inoculação coincidem com as apreciações de Emechebe \& Mukiibi (1976), Lin \& Chang (1985) e Cedeño et al. (1990) de que $N$. haematococca é um patógeno que causa doença unicamente na presença de ferimentos. Emechebe \& Mukiibi (1976) sugeriram que o processo infeccioso é favorecido pelas lesões provocadas pela emergência das raízes laterais, implementos agrícolas, insetos habitantes do solo e nematóides. O patógeno $P$. nicotianae, ao contrário de $N$. haematococca, mostrou-se capaz de infetar diretamente os tecidos de plântulas, como também observado por Cole et al. (1992) e Gonzalez et al. (2000), embora a suscetibilidade diminua com a idade das plântulas. Os maiores índices de "damping-off" quando os patógenos estavam associados podem ser explicados pela porta de entrada provocada por $P$. nicotianae à infecção de $N$. haematococca. Segundo Cole et al. (1992), a dessecação dos tecidos infetados indica que apenas $N$. haematococca efetivamente colonizou o tecido, porém na presença de $P$. nicotianae a extensão do tecido invadido foi maior.

A época de inoculação pode interferir no desenvolvimento da doença, como já observado por Matta (1982). No presente trabalho foi verificado que plantas inoculadas em março de 2002 apresentaram maior intensidade de doença, quando comparado a maio do mesmo ano, devido, prova-

TABELA 6 - Comprimento de lesões (cm) e número de plantas mortas de genótipos de Passiflora edulis f. flavicarpa, inoculados com diferentes isolados de Nectria haematococca no colo das plantas

\begin{tabular}{|c|c|c|c|c|}
\hline \multirow{2}{*}{$\begin{array}{l}\text { Isolado de Nectria } \\
\text { haematococca }\end{array}$} & Maguari & Sapucaí (SP) & IAC-270 & Sul -Brasil \\
\hline & Mortes/lesão $(\mathrm{cm})^{*}$ & Mortes/lesã $(\mathrm{cm})^{*}$ & Mortes/lesã $(\mathrm{cm})^{*}$ & Mortes/lesão $(\mathrm{cm})^{*}$ \\
\hline Sussuarana (BA) & $4 / 1,75$ & $1 / 1,84$ & $2 / 1,30$ & $5 / 1,20$ \\
\hline Vera Cruz (SP) & $1 / 1,34$ & $2 / 1,23$ & $3 / 1,20$ & $4 / 1,55$ \\
\hline Populina (SP) & $0 / 1,28$ & 1,67 & 1,00 & $4 /$ \\
\hline Jaú (SP) & $0 / 1,50$ & $0 / 1,22$ & $1 /$ & $2 / 1,55$ \\
\hline Monte A. P. (SP) & $0 / 0,75$ & $0 / 0,95$ & $1 / 0,84$ & $1 / \mathbf{0 , 7 0}$ \\
\hline
\end{tabular}

* Média de lesões das plantas sobreviventes de um total de seis plantas, após seis meses da inoculação de $N$. haematococca.

TABELA 7 - Porcentagem de inibição do crescimento micelial de Nectria haematococca do maracujazeiro em meio batatadextrose-ágar, acrescido de diferentes fungicidas e concentrações, em relação à testemunha cultivada em meio sem adição de fungicida (resultados de dois experimentos)

\begin{tabular}{|c|c|c|c|c|c|c|c|c|c|c|}
\hline \multirow{2}{*}{ Ingrediente Ativo } & \multicolumn{5}{|c|}{ N. haematococca (Vera Cruz, SP) } & \multicolumn{5}{|c|}{ N. haematococca (Sussuarana, BA) ${ }^{1}$} \\
\hline & \multicolumn{2}{|c|}{1 ppm } & \multicolumn{2}{|c|}{10 ppm } & 100 ppm & 1 ppm & \multicolumn{2}{|c|}{10 ppm } & \multicolumn{2}{|c|}{$100 \mathrm{ppm}$} \\
\hline Prochloraz & 78,82 & $\mathbf{a}^{2}$ & 93,95 & $a^{2}$ & 100,00 & $84,77 \mathrm{a}^{2}$ & 98,94 & $a^{2}$ & 100,00 & \\
\hline Thiabendazole & 78,95 & $\mathbf{a}$ & 84,34 & $\mathbf{a}$ & $97,63 \mathrm{a}$ & $80,69 \mathrm{ab}$ & 86,58 & b & 96,38 & $\mathbf{a}$ \\
\hline Thiram +thiabend. & 81,32 & $\mathbf{a}$ & 86,45 & $\mathbf{a}$ & 94,11 a & $67,51 \mathrm{c}$ & 81,75 & b & 96,83 & a \\
\hline Benomyl & 65,00 & bc & 88,03 & $\mathbf{a}$ & $92,76 \mathrm{a}$ & $67,27 \mathrm{c}$ & 88,84 & $\mathbf{a b}$ & 93,82 & $\mathbf{a b}$ \\
\hline Carbendazim & 68,95 & $\mathbf{b}$ & 85,79 & a & 90,79 a & $77,68 \mathrm{~b}$ & 88,24 & $a b$ & 91,10 & $\mathbf{b}$ \\
\hline Triflumizole & 28,95 & g & 52,89 & bcd & $75,66 \mathrm{~b}$ & $25,07 \mathrm{~h}$ & 48,24 & def & 71,34 & $\mathrm{c}$ \\
\hline Captan & $-0,92$ & i & 1,84 & $\mathrm{~h}$ & $64,34 \mathrm{~cd}$ & $13,75 \mathbf{i j}$ & 21,87 & i & 68,63 & $\mathrm{c}$ \\
\hline Tiofanato met ílico & 1,84 & hi & 42,37 & def & $67,76 \mathrm{bc}$ & $2,71 \mathrm{~lm}$ & 46,00 & defg & 63,20 & d \\
\hline Thiram+vitavax & 1,05 & hi & 11,84 & gh & $53,29 \mathrm{fg}$ & $9,20 \quad \mathrm{jk}$ & 22,32 & i & 62,74 & d \\
\hline Difenoconazole & 35,00 & $\mathrm{f}$ & 46,05 & cdef & $64,74 \mathrm{~cd}$ & $30,69 \mathrm{~g}$ & 46,84 & defg & 55,81 & e \\
\hline Hexaconazole & 44,21 & $\mathrm{e}$ & 48,29 & cdef & $56,58 \operatorname{defg}$ & $43,74 \mathrm{f}$ & 53,08 & de & 59,28 & de \\
\hline Fluazinam & 56,84 & d & 56,58 & bc & 61,84 cde & $50,07 \mathrm{e}$ & 53,24 & de & 57,62 & e \\
\hline Thiram & 5,92 & $\mathrm{~h}$ & 17,37 & $\mathrm{~g}$ & 58,55 def & $9,50 \mathrm{jk}$ & 33,34 & ghi & 58,52 & e \\
\hline Iprodione & 60,79 & cd & 61,18 & b & 56,84 defg & $56,26 \mathrm{~d}$ & 57,16 & cd & 57,47 & $\mathbf{e}$ \\
\hline Chlorothalonil & 27,63 & g & 44,74 & cdef & $54,34 \mathrm{efg}$ & $28,51 \mathrm{gh}$ & 55,98 & cd & 57,92 & $\mathbf{e}$ \\
\hline Procimidone & 4,87 & $\mathrm{~h}$ & 46,05 & cdef & $48,82 \mathrm{gh}$ & $17,04 \mathrm{i}$ & 38,16 & j & 44,95 & fg \\
\hline Fluodioxonil & 62,89 & $\mathrm{c}$ & 50,66 & bcde & $51,32 \mathrm{fg}$ & $57,77 \mathrm{kl}$ & 65,46 & $\mathrm{c}$ & 36,65 & $\mathrm{~h}$ \\
\hline Mancozeb & 5,26 & $\mathrm{~h}$ & 18,68 & $\mathrm{~g}$ & $42,89 \mathrm{hi}$ & $7,09 \quad \mathrm{kl}$ & 21,87 & $\mathrm{i}$ & 42,38 & $\mathrm{~g}$ \\
\hline Kresoxim metil & 35,13 & $f$ & 37,37 & $\mathrm{f}$ & $36,84 \mathrm{i}$ & $31,53 \mathrm{~g}$ & 32,88 & hi & 36,80 & $\mathrm{~h}$ \\
\hline Azoxystrobin & 32,89 & $\mathrm{fg}$ & 39,87 & ef & $36,32 \mathrm{i}$ & $30,62 \mathrm{~g}$ & 33,94 & ghi & 31,52 & i \\
\hline Pencycur on & 1,05 & $\mathrm{hi}$ & 1,58 & $\mathrm{~h}$ & $6,18 \quad j$ & $2,26 \mathrm{~m}$ & 4,07 & $\mathrm{j}$ & 8,60 & $\mathbf{j}$ \\
\hline Oxicloreto de cobre & 1,32 & hi & $-0,53$ & $\mathrm{~h}$ & $-0,79 j$ & $3,17 \quad 1$ & 5,28 & $\mathrm{j}$ & 0,45 & $\mathrm{k}$ \\
\hline C.V. $(\%)$ & 6,62 & & 11,3 & & 6,09 & 6,16 & 10,8 & & 3,17 & \\
\hline
\end{tabular}

${ }^{1}$ Média de cinco repetições aos sete dias de incubação.

${ }^{2}$ Médias seguidas pela mesma letra na coluna não diferem entre si (Tukey, p <0,05). 
Seleção de plantas resistentes e de fungicidas para o controle...

TABELA 8 - Efeito de fungicidas no comprimento (cm) de lesões ou morte de maracujazeiro (Passiflora edulis f. flavicarpa) (+) causada por Nectria haematococca, aplicados aos dois (2 d) ou sete dias (7 d) após a inoculação

\begin{tabular}{|c|c|c|c|c|c|c|c|c|c|c|c|}
\hline \multirow{2}{*}{ Passiflora edulis f. flavicarpa } & \multirow{2}{*}{$\begin{array}{l}\text { testem. } \\
\text { inocul. }\end{array}$} & \multicolumn{2}{|c|}{ prochloraz } & \multicolumn{2}{|c|}{ thiabendazole } & \multicolumn{2}{|c|}{ carbendazim } & \multicolumn{2}{|c|}{ triflumizole } & \multicolumn{2}{|c|}{ difenoconazole } \\
\hline & & $2 d$ & $7 \mathrm{~d}$ & $2 \mathrm{~d}$ & $7 \mathrm{~d}$ & $2 \mathrm{~d}$ & $7 \mathrm{~d}$ & $2 \mathrm{~d}$ & $7 \mathrm{~d}$ & $2 \mathrm{~d}$ & $7 \mathrm{~d}$ \\
\hline $1^{1}$ & + & 1,2 & 1,8 & $+^{2}$ & 1,6 & 1,6 & 1,9 & 1,4 & + & + & 2,3 \\
\hline 2 & + & 0,9 & 1,5 & $t^{2}$ & 0,9 & 1,1 & 1,6 & 1,0 & 1,3 & 1,4 & 1,8 \\
\hline 3 & 2,1 & 0,9 & 0,9 & $t^{2}$ & 0,9 & 1,1 & 1,2 & 1,0 & 1,1 & 1,4 & 1,4 \\
\hline 4 & 1,6 & 0,8 & 0,8 & 0,8 & 0,6 & 0,7 & 1,0 & 0,9 & 1,0 & 1,0 & 1,1 \\
\hline 5 & 0,7 & 0,6 & 0,6 & 0,6 & 0,6 & 0,7 & 0,9 & 0,8 & 0,8 & 0,8 & 0,9 \\
\hline
\end{tabular}

${ }^{1}$ Repetição = planta de Passiflora edulis f. flavicarpa .

${ }^{2}$ Morte causada por fitotoxidez

velmente, às temperaturas maiores, com médias de $28{ }^{\circ} \mathrm{C}$ em março e $26^{\circ} \mathrm{C}$ em maio, sob casa de vegetação.

O maracujá-amarelo 'Sul-Brasil' apresentou elevada suscetibilidade a Nectria comparado aos outros genótipos. Segundo Menezes (1990) e Nogueira Filho (2003) espécies como $P$. alata, $P$. giberti, $P$. quadrangularis, $P$. macrocarpa Mast., $P$. coccinea e $P$. nitida mostraram-se passíveis de utilização como porta-enxertos para o maracujazeiro amarelo, embora diferentes níveis de compatibilidade tenham sido observados. Yamashiro \& Landgraff (1979) indicaram P. alata como um promissor porta-enxerto, pois além de ser resistente ao patógeno causador da "murcha", confere à copa maior precocidade e não apresenta alteração na qualidade dos frutos, permitindo também o uso de solos mais úmidos (favoráveis ao patógeno).

A alta variabilidade genética de $P$. edulis f.flavicarpa, perceptível pelas diferenças na suscetibilidade ao patógeno, condiz ao observado em outros trabalhos. Delanoë (1991) classificou a espécie como altamente suscetível a $N$. haematococca, Ssekyewa et al. (1999) a consideraram parcialmente resistente, enquanto Lin \& Chang (1985) encontraram algumas linhagens resistentes ao patógeno, indicando a possibilidade do melhoramento genético intraespecífico ser mais promissor, considerando aspectos favoráveis de compatibilidade e produtividade da espécie.

Resultados promissores foram obtidos com os fungicidas em tratamento erradicante, inibindo o processo infeccioso e reduzindo o desenvolvimento da doença através do emprego de fungicidas sistêmicos. Atenção aos sintomas iniciais da doença aumenta as chances de sucesso do controle químico curativo, pois um melhor índice de controle é obtido com a doença em seu estágio inicial. Em áreas com histórico da doença um controle químico preventivo poderá ser indicado após práticas culturais que ocasionem ferimentos (transplante, coroamento) e durante as estações quentes e úmidas.

\section{REFERÊNCIAS BIBLIOGRÁFICAS}

BOOTH, C. Fusarium: Laboratory guide to identification of the major species. Kew, Surrey: Commonweath Mycological Institute, 1977. $17 \mathrm{p}$.

CEDEÑO, L., PALACIOS-PRU, E., MARQUES, N.J. \& TAVIRA, M.E. Nectria haematococca, agente causal de la muerte repentina de la parchita em Venezuela. Fitopatología Venezolana 3:15-18. 1990.

COLE, D.L., HEDGES, R. \& NDOWORA, T. A wilt of passion fruit (Passiflora edulis f. edulis Sims) caused by Fusarium solani and Phytophthora nicotianae var. nicotianae. Tropical Pest Management 38:362-366. 1992.

DELANOË, O. Etude de la résistance de passiflores de Guyane française vis-à-vis de Fusarium pathogènes de la culture des fruits de la Passion (Passiflora edulis f. flavicarpa). Fruits 46:593-600. 1991.

EMECHEBE, A.M. \& MUKIIBI, J. Nectria collar and root rot of passion fruit in Uganda. Plant Disease Reporter 60:227-231. 1976. FISCHER, I.H., KIMATI, H. \& HAMAGUSHI, W. Ocorrência de Fusarium solani e Phytophthora nicotianae, causando morte prematura do maracujazeiro em Vera Cruz, SP. Summa Phytopathologica 29:54. 2003a.

FISCHER, I.H., MARTINS, M.C., LOURENCO, S.A., KIMATI, H. \& AMORIM, L. Reação de espécies de Passiflora à podridão do colo, causada por Fusarium solani e Phytophthora nicotianae. Fitopatologia Brasileira 28:271. 2003b.

GONZALEZ, M.S., SUAREZ, Z. \& ROSALES, C. Collar rot and wilt of yellow passion fruit in Venezuela. Plant Disease 84:103. 2000.

LIN, Y.S. \& CHANG, H.J. Collar rot of passion fruit possibly caused by Nectria haematococca in Taiwan. In: Parker, C.A., Rovira, A.D., Moore, K.J., Ong, P.T.W. \& Kollmorgen, J.F. (Eds.). Ecology and management of soilborne plant pathogens. St. Paul: APS Press, 1985. pp.41-45.

MATTA, E.A.F. Doenças do maracujazeiro no Estado da Bahia. Salvador: EPABA, 1982. 17p. (Circular Técnica, 2).

MELO, M.B., BATISTA, F.A.S., SILVA, L.M.S. \& TRINDADE, J. Controle da podridão de raízes do maracujazeiro Passiflora edulis f. flavicarpa Deg. Revista Brasileira de Fruticultura 5:7-12. 1990.

MENEZES, J.M.T. Seleção de porta-enxertos tolerantes a morte prematura de plantas para Passiflora edulis Sims f. flavicarpa Deg. e comportamento de Passiflora nitida HBK na região de Jaboticabal. Jaboticabal, 1990. 73p. Dissertação (Mestrado) - Faculdade de Ciências Agrárias e Veterinárias - Campus de Jaboticabal, Universidade Estadual Paulista.

MITCHELL, D.J. \& KANNWISCHER-MITCHELL, M.E. Phytophthora. In: Singleton, L.L., Mihail, J.D. \& Rush, C.M. (Eds.) Methods for Research on Soilborne Phytopathogenic Fungi. St. Paul, Minnesota: APS Press, 1992. cap.2, pp.31-38.

NOGUEIRA FILHO, G.C. Competição de sete Passifloraceas como 
porta-enxertos para o maracujazeiro amarelo através de enxertia hipocotiledonar. Jaboticabal, 2003. 113p. Tese (Doutorado em Agronomia, Área de Produção Vegetal) - Faculdade de Ciências Agrárias e Veterinárias, Universidade Estadual Paulista, Jaboticabal, 2003.

NUNES, A.M.L. \& ALBUQUERQUE, F.C. Podridão do coleto do maracujazeiro (Passiflora edulis). Fitopatologia Brasileira 20:356. 1995.

PONTE, J.J. da. As doenças do maracujá-amarelo no nordeste do Brasil. Revista Brasileira de Fruticultura 15:11-14. 1993.

PONTE, J.J. da., FRANCO, A., AGUIÁR DE HOLANDA, Y.C. \& SILVEIRA FILHO, J. Calagem, adubação orgânica e fungicida de solo no controle da podridão do pé (Fusarium solani) do maracujáamarelo. Fitopatología Venezolana 12:30-31. 1998.
RUGGIERO, C., SÃO JOSE, A.R., VOLPE, C.A., OLIVEIRA, J.C., DURIGAN, J.F., BAUMGARTNER, J.G., DA SILVA, J.R., NAKAMURA, K.I., FERREIRA, M.E., KAVATI, R. \& PEREIRA, V.P. Maracujá para exportação: aspectos técnicos da produção. Brasília: Frupex-Embrapa, 1996. 63p.

SSEKYEWA, C., FINA OPIO, A., SWINBURNE, T.R., VAN DAMME, P.L.V. \& ABUBAKAR, Z.M. Sustainable management of collar rot disease of passion fruits in Uganda. International Journal of Pest Management 45:173-177. 1999.

YAMASHIRO, T. \& LANDGRAFF, J.H. Maracujá-açu (Passiflora alata Ait), porta-enxerto resistente à fusariose do maracujazeiro (Passiflora edulis f. flavicarpa Deg.). In: Congresso Brasileiro de Fruticultura, 5., Pelotas, 1979. Anais. Pelotas, RS: Sociedade Brasileira de Fruticultura, 1979. pp.918-921. 